Bach, F., and Hirschhorn, K. (1964). Science, 143, 813.

Bain, B., and Lowenstein, L. (1964). Ibid., 145, 1315.

Bain, B., and Lowenstein, L. (1964), Ibid., 145, 1315. $23,108$.

Brent, L., and Medawar, P. B. (1963). Brit. med. F., 2, 269.

Brent, L., and Medawar, P. B. (1963). Brit. Med
(1964). Nature (Lond.), 204, 90.

Bridges, J. M., Nelson, S. D., and McGeown, M. G. (1964). Lancet, 1 , 581 .

Chen, P. S. (1958). Proc. Soc. exp. Biol. (N.Y.), 98, 546.

Gray, J. G., and Russell, P. S. (1963). Lancet, 2, 863.

(1965). In Histocompatibility Testing, edited by P. S. Russell p. 105 .
Harris, R., Clarke, C. A., Jones, A. L., Sheppard, P. M., Lehane, D., McCarthy, M., Lawler, S. D., and Shatwell, H. S. (1966). Bri. med. F., 1, 509.

Hirschhorn, $\mathrm{K}$ (1965). In Histocompatibility Testing, edited by P. S. Russell and H. J. Winn, Publication No. 1229, Nat. Acad. Sci., Washington, p. 177 .

Huggins, C. E. (1964). Ann. Surg., 160, 643.

Johnson, G. J., and Russell, P. S. (1965). Nature (Lond.), 208, 343.

Moorhead, J. F., and Patel, A. R. (1964). Brit. med. 7., 2, 1111

Russell, P. S. (1966). In Histocompatibility Testing 1965 , edited by $\mathrm{H}$. Balner, F. J. Cleton, and J. G. Eernisse, p. 233. Copenhagen.

Streilein, J. W. (1966). Ibid., p. 241.

\title{
Conversion of Cortisone to Cortisol and Prednisone to Prednisolone
}

\author{
J. S. JENKINS,* M.D., M.R.C.P. ; P. A. SAMPSON, $\dagger$ M.B., CH.B.
}

Brit. med.f., 1967, 2, 205-207

Though cortisone has been widely used since Hench et al. (1949) described its value in the treatment of rheumatoid arthritis, there is now considerable evidence that cortisone and other steroids which possess the 11-oxo group instead of a $11 \beta$-hydroxyl are themselves biologically inactive. The direct application of cortisone to the skin is ineffective in the treatment of skin diseases responsive to cortisol (Robinson and Robinson, 1956), and when cortisone is injected locally into inflamed joints its anti-inflammatory action is slight compared with that of cortisol (Hollander et al., 1951). It is the reduction of the 11-oxo to the $11 \beta$-hydroxyl by the enzyme $11 \beta$-hydroxydehydrogenase which renders the 11-oxo steroids cortisone and its synthetic analogue prednisone biologically active when they are administered systemically. In man this reaction appears to take place mainly in the liver (Jenkins, 1966). Several investigators have made clinical comparisons of the therapeutic effects of cortisone and cortisol and of prednisone and prednisolone, but there is less information about the actual amounts of $11 \beta$-hydroxysteroids which are formed from the 11-oxo compounds. Peterson et al. (1957b) described the conversion of cortisone to cortisol in one patient, but the results were complicated by the prior administration of $9 \alpha$-fluoroprednisolone to the patient. Bush and Mahesh (1964) studied the reduction of prednisone, again in only one patient, but no comparison was made with the levels of prednisolone in the plasma after prednisolone itself. The present paper describes the extent to which oral cortisone and prednisone are converted to cortisol and prednisolone in a series of normal subjects, and also in patients suffering from liver disease.

\section{Procedure and Methods}

Nine normal subjects, three patients with Addison's disease, and four patients suffering from disease of the liver, were given single oral doses of cortisone or prednisone as crushed tablets in amounts ranging from 25 to $200 \mathrm{mg}$. On subsequent occasions a similar dose of cortisol or prednisolone was given to the same subjects. At hourly intervals after the administration of cortisone and cortisol the levels of cortisol in the plasma were compared. Similarly, the levels of prednisolone in the plasma were measured after giving prednisone and prednisolone. Cortisone was administered mostly as the acetate, since this is the usual form available for therapeutic use, but in some instances the free alcohol was also given for comparison. Cortisol, prednisone, and prednisolone were given as the free alcohol.

\footnotetext{
* Consultant Physician, St. George's Hospital, London S.W.1.
}

† Research Assistant, St. George's Hospital, London S.W.1.
After their oral administration the absorption of each of the pair of steroids was compared by measuring the total 24-hour excretion of 17-oxogenic steroids in the urine.

Cortisol in Plasma.-A fluorimetric technique (Rudd et al., 1963) was used, by means of which cortisol can be measured without interference from cortisone or other metabolites. In some cases plasma cortisol, tetrahydrocortisol, cortisone, and tetrahydrocortisone were estimated specifically by a paper chromatographic technique similar to that described for the estimation of plasma prednisolone, the appropriate standard steroids being used.

Prednisolone in Plasma.-Five millilitres of heparinized plasma was extracted with $25 \mathrm{ml}$. of methylene chloride, and the extract was washed first with $2 \mathrm{ml}$. of 0.1 normal sodium hydroxide, followed by 0.1 normal acetic acid and finally with water. The extract was evaporated to dryness, redissolved in a small volume of a mixture of methanol and methylene chloride, and applied to Whatman No. 1 chromatography paper. Chromatograms were run for four hours in the benzenemethanol-water (100:50:50) system of Bush (1952). The prednisolone area was located by ultraviolet light and eluted with methanol from the chromatogram. The eluate was taken to dryness, redissolved in $0.5 \mathrm{ml}$. of methylene chloride, and the steroid estimated, the phenylhydrazinesulphuric acid reagent of Porter and Silber (1950) being used according to the technique of Peterson et al. (1957a). Standard amounts of prednisolone were taken through the whole procedure.

17-Oxogenic steroids in the urine were estimated by the method of Appleby et al. (1955).

\section{Conversion of Cortisone to Cortisol}

The mean levels of cortisol in the plasma after the oral administration of 100 or $200 \mathrm{mg}$. of cortisone and cortisol to normal subjects and $25 \mathrm{mg}$. of these steroids to patients with Addison's disease are shown in Fig. 1 . No significant difference was seen in the levels obtained with cortisone acetate and the free alcohol when both were given to some of the subjects on different occasions, and they have therefore not been recorded separately. The peak level after cortisone was normally at two hours, but in all cases was lower than the peak after cortisol. This difference became disproportionately greater as the dosage increased up to $200 \mathrm{mg}$., when plasma cortisol after cortisone was only a third to half the level after cortisol. The various unconjugated steroids present in the plasma of a normal subject two hours after $200 \mathrm{mg}$. of cortisone and cortisol were examined chromatographically, and are shown in Table I. The cortisol 
level after cortisone in this subject was approximately one-half that after cortisol, but this difference was represented to only a small extent by unreduced cortisone. It can be seen that after cortisone a greater amount of tetrahydrocortisone was present than after cortisol, so that much of the cortisone was reduced at ring $\mathrm{A}$ without reduction of the 11-oxo group.

Table I.-Plasma Unconjugated Steroids in Normal Subject Two Hours After Oral Cortisone and Cortisol ( $\mu \mathrm{g} . / 100 \mathrm{ml}$.)

\begin{tabular}{|c|c|c|c|}
\hline \multicolumn{2}{|c|}{ Steroid in Plasma } & $\begin{array}{l}\text { After Cortisone } \\
(200 \mathrm{mg} .)\end{array}$ & $\begin{array}{l}\text { After Cortisol } \\
\text { (200 mg.) }\end{array}$ \\
\hline $\begin{array}{l}\text { Cortisol } \quad . \quad \text {. } \\
\text { Cortisone } \quad \text { Tetrahydrocortisol } \\
\text { Tetrahydrocortisone: }\end{array}$ & $\begin{array}{l}\cdots \\
\because \\
\cdots\end{array}$ & $\begin{array}{l}62 \cdot 0 \\
19 \cdot 4 \\
59 \cdot 4 \\
66 \cdot 6\end{array}$ & $\begin{array}{c}\frac{135 \cdot 4}{71 \cdot 4} \\
34 \cdot 4\end{array}$ \\
\hline
\end{tabular}

Urinary 17-oxogenic steroids after cortisone given either as the acetate or the free alcohol were $90 \%$ or more of those obtained after cortisol, indicating that cortisone was absorbed only slightly less well than cortisol.

\section{Conversion of Prednisone to Prednisolone}

The levels of plasma prednisolone after the administration of $100 \mathrm{mg}$. of prednisone and $100 \mathrm{mg}$. of prednisolone are shown for three normal subjects in Fig. 2. The plasma cortisol for these same subjects when previously given cortisone and cortisol in the same dosage is also shown for comparison. It can be seen that, in contrast to the relatively low levels of cortisol achieved after cortisone, the levels of prednisolone in the plasma after prednisone closely followed those obtained after prednisolone itself. It is also of interest that the peak value after prednisolone was twice the cortisol value after a similar dose of cortisol. The yield of 11-hydroxysteroid obtained with prednisone was three to four times that obtained with an equal amount of cortisone.

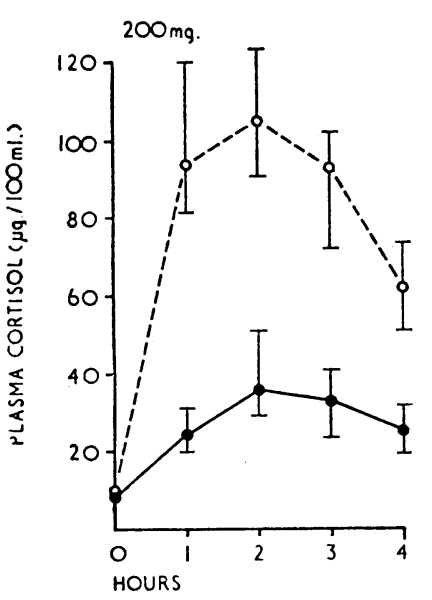

$$
100 \mathrm{mg} \text {. }
$$
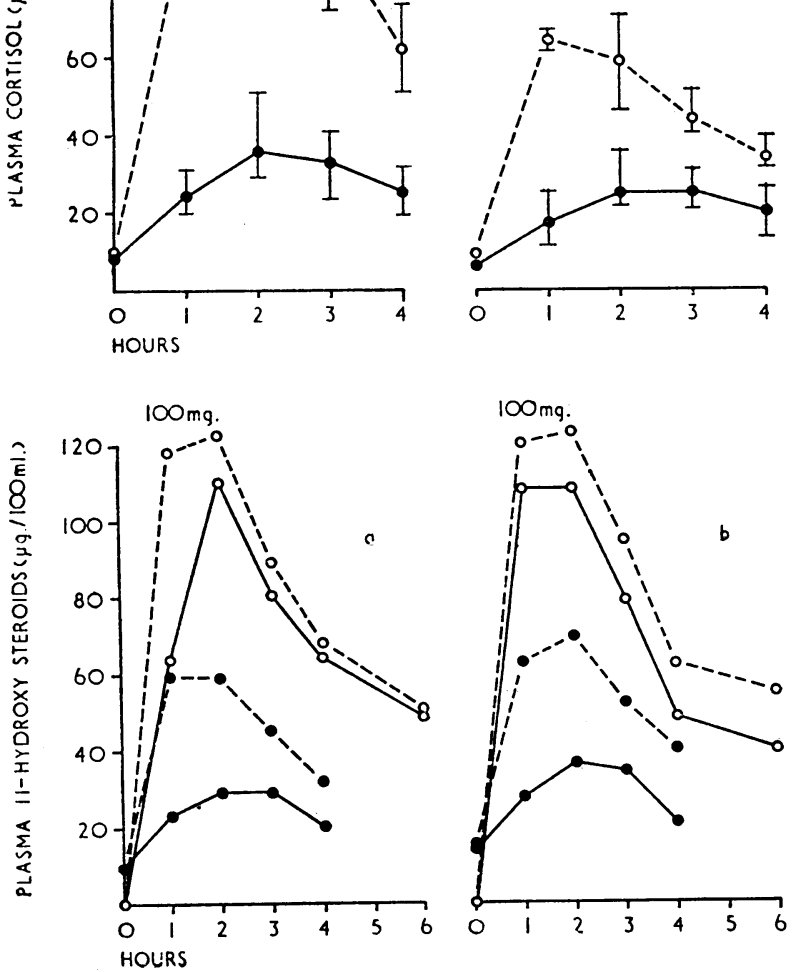

$100 \mathrm{mg}$

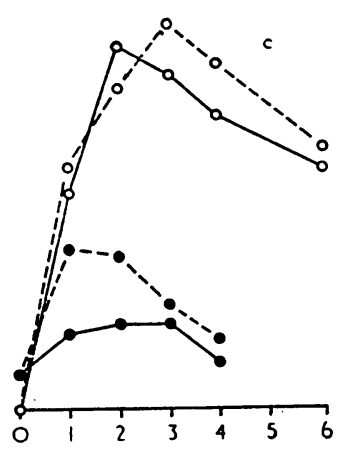

Fig. 1.-Plasma cortisol levels after cortisone indicated by , and after cortisol indicated by $\mathrm{O}-\mathrm{O}$. The mean and range of values are for five normal subjects given $200 \mathrm{mg}$. of each steroid, four normal subjects given $100 \mathrm{mg}$., and three patients with Addison's disease given $25 \mathrm{mg}$.
Fig. 2.-Plasma prednisolone levels in three FIg. 2.-Plasma prednisolone levels in three none indicated by $\mathrm{O}$, $\mathrm{O}$ and after $100 \mathrm{mg}$. of sone indicated by $\mathrm{O}-\mathrm{O}$ and after $100 \mathrm{mg}$. of prednusolone indicated by $\mathrm{O}-\ldots \mathrm{O}$. The lower two curves show plasma cortisol values in the same subjects given $100 \mathrm{mg}$. cortisone indicated by and cortisol indicated by 
subject. On the other hand, much more cortisone remained unconverted, and both findings can be explained on the impairment of ring A reduction, shown by the much lower values for tetrahydrocortisol in the cirrhotic patient.

TABLE II.-Plasma Unconjugated Steroids in a Normal and a Cirrhotic Subject Two Hours After Oral Cortisone and Cortisol ( $\mu \mathrm{g} . / 100 \mathrm{ml}$.)

\begin{tabular}{|c|c|c|c|c|}
\hline \multicolumn{3}{|c|}{ Steroid in Plasma } & Normal & Cirrhosis \\
\hline & & & \multicolumn{2}{|c|}{ After cortisone (200 mg.) } \\
\hline \multirow[t]{2}{*}{$\begin{array}{l}\text { Cortisol } \\
\text { Cortison }\end{array}$} & $\because$ & $\therefore$ & $\begin{array}{l}52 \cdot 0 \\
20 \cdot 5\end{array}$ & $\begin{array}{l}88 \cdot 0 \\
93 \cdot 5\end{array}$ \\
\hline & & & \multicolumn{2}{|c|}{ After cortisoi (200 mg.) } \\
\hline $\begin{array}{l}\text { Cortisol } \\
\text { Tetrahydrocortisol }\end{array}$ & $\cdots$ & $\because$ & $\begin{array}{r}100 \cdot 0 \\
60 \cdot 2\end{array}$ & $\begin{array}{r}132 \cdot 4 \\
25 \cdot 2\end{array}$ \\
\hline
\end{tabular}

Prednisone and Prednisolone.-Fig. 4 shows the conversion of prednisone to prednisolone in a patient with infectious hepatitis and another with hepatic cirrhosis who were given $50 \mathrm{mg}$. of prednisone and prednisolone. In one patient plasma prednisolone levels were almost identical after the two steroids, and in the other patient conversion of prednisone to prednisolone was considerable.

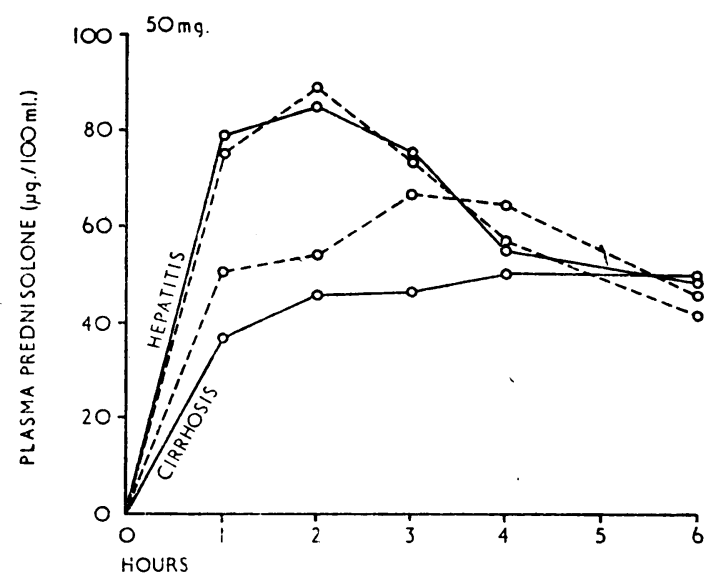

FIG. 4.-Plasma prednisolone levels in two patients with liver disease given $50 \mathrm{mg}$. of prednisone indicated by O - - O.

\section{Discussion}

The lower cortisol level found in the plasma after the administration of cortisone, which amounted to only a third to a half that obtained with cortisol at the 200-mg. dosage, was not due simply to large differences in absorption, since in agreement with Cope and Black (1958) this difference was only about $10 \%$. Chromatographic analysis revealed that the lower peak value after cortisone was due only in part to unmetabolized cortisone. The presence of large amounts of tetrahydrocortisone indicated that some of the cortisone was wasted, from a biological point of view, by reduction in ring $A$ instead of at the 11-oxo group. It seemed that the capacity of cortisone to be converted to cortisol by $11 \beta$-hydroxydehydrogenase in the liver was limited by competition from the liver enzymes concerned with reduction of the A ring, and this was particularly apparent when large doses of cortisone were given. In contrast, prednisone was converted to prednisolone with a much higher degree of efficiency than cortisone to cortisol, and this would follow from the relative lack of ring $A$ reduction which is known to occur in these 1,2-dehydrosteroids (Sandberg and Slaunwhite, 1957). The much higher levels achieved in the plasma after the administration of prednisolone compared with plasma cortisol after cortisol administration may be an indication of the differences in the degree to which the A ring is reduced.

These results are at variance with those of Bush and Mahesh (1964), who, in a single patient, claimed that the 11-oxo group of prednisone was reduced to a less degree than was the case with cortisone, but this would imply that prednisone was biologically less active in relation to prednisolone than cortisone was in relation to cortisol. The results reported here, however, are in accordance with previous clinical findings; Bunim et al. (1955) found that prednisone and prednisolone were approximately equivalent in their therapeutic effects. Boland (1952) found that cortisone, either as the free alcohol or as the acetate, was only one-half to two-thirds as effective as cortisol at the $40-60-\mathrm{mg}$. dosage in the maintenance treatment of rheumatoid arthritis.

The results obtained from the patients with liver disease are of interest, since, although the liver is thought to be the main site for reduction of the 11-oxo group, there was considerable preservation of the ability to carry out this reaction in all cases. There was, on the other hand, marked impairment of ring $A$ reduction, as reported previously by other investigators (Peterson, 1960). It is of course possible that more severe degrees of liver disease than those studied would show more evidence of an impairment of 11-oxo reduction. From the practical point of view these results indicate that even in the presence of normal liver function much of the cortisone is not converted to cortisol, and there would seem to be a good reason for using cortisol itself whenever this steroid is required orally, whereas prednisone and prednisolone are almost equivalent in their action. Though liver disease appeared to have little significant effect on the reduction of the 11-oxo group of cortisone and prednisone, the number of cases was limited, and if steroid therapy is required in the presence of severe liver disease it is probably wise to use the $11 \beta$-hydroxysteroids cortisol or prednisolone in order to ensure a full therapeutic effect.

\section{Summary}

The conversion of cortisone and prednisone to the biologically active steroids cortisol and prednisolone has been studied in normal patients and in liver disease. The cortisol levels in the blood in normal subjects after oral cortisone were much lower than after cortisol itself, especially when high doses were used.

In contrast, prednisone was converted to prednisolone with a high degree of efficiency. The difference appeared to be due to reduction of some of the cortisone to tetrahydrocortisone, whereas prednisone does not readily form tetrahydro derivatives.

In four patients with liver disease, reduction of the 11-oxo group of cortisone and prednisone, which is necessary for biological activity, was well maintained.

We wish to thank Roussel Laboratories for the supply of cortisone (free alcohol). One of us (J.S. J.) was in receipt of a research grant from the Governors of St. George's Hospital, and the other (P. A. S.) was supported by a Medical Research Council grant.

\section{REFERENCES}

Appleby, J. I., Gibson, G., Norymberski, J. K., and Stubbs, R. D. (1955). Biochem. 7., 60, 453 .

Boland, E. W. (1952). Brit. med. 7., 1, 559.

Bunim, J. J., Pechet, M. M., and Bollet, A. J. (1955). F. Amer. med. Ass., 157,311 .

Bush, I. E. (1952). Biochem. 7., 50, 370.

Cond Mahesh, V. B (1964). Ibid., 93, 236.

Cope, C . M and Black, E. G. (i958). Clin. Sci., 17, 147.

Hench, P. S., Kendall, E. C., Slocumb, C. H., and Polley, H. F. (1949). Proc. Mayo Clin., 24, 181 .

Hollander, J. L., Brown, E. M., Jessar, R. A., and Brown, C. Y. (1951). 7. Amer. med. Ass., 147, 1629 .

Jenkins, J. S. (1966). F. Endocr., 34, 51

Peterson, R. E. (1960). F. clin. Invest., 39, 320

- Karrer, A., and Guerra, S. L. (1957a). Analyt. Chem., 29, 144 Pierce, C. E., W yngaarden, J. B., Bunim, J. J., and Brodie, B. B. (19J7b). 尹. clin. Invest., 36, 1301.

Porter, C. C., and Silber, R. H. (1950). 7. biol. Chem., 185, 201. Robinson, R.' C. V., and Robinson, H. M. (1956). Sth. med. F. (Bgham,

Rudd, B. T., Sampson, P., and Brooke, B. N. (1963). J. Endocr., 27, 317. Sandberg, A. A., and Slaunwhite, W. R. (1957). 7. clin. Endocr., 17, 